\title{
Novel Approach in Sampling and Tensile Strength Evaluation of Roots to Enhance Soil for Preventing Erosion
}

\author{
Shaurav Alam ${ }^{*}$, Ashlesh Banjara ${ }^{1}$, Jay Wang1 ${ }^{1}$, William B. Patterson ${ }^{2}$, Sujan Baral ${ }^{1}$ \\ ${ }^{1}$ Program of Civil Engineering, Louisiana Tech University, Ruston, LA, USA \\ ${ }^{2}$ School of Agricultural Sciences and Forestry, Louisiana Tech University, Ruston, LA, USA \\ Email: *shaurav@latech.edu
}

How to cite this paper: Alam, S., Banjara, A., Wang, J., Patterson, W.B. and Baral, S. (2018) Novel Approach in Sampling and Tensile Strength Evaluation of Roots to Enhance Soil for Preventing Erosion. Open Journal of Soil Science, 8, 330-349. https://doi.org/10.4236/ojss.2018.812024

Received: November 21, 2018 Accepted: December 22, 2018 Published: December 25, 2018

Copyright $\odot 2018$ by authors and Scientific Research Publishing Inc. This work is licensed under the Creative Commons Attribution International License (CC BY 4.0).

http://creativecommons.org/licenses/by/4.0/

\begin{abstract}
This paper presents novel approaches to address the complex issues associated with preservation, transportation, and tensile testing of the vegetation root samples needed for the enhancement of soil and prevent erosion. Readily availability of no equipment for in-situ assessment of the roots' contribution to soil strength forces the researchers to transport the root samples to the lab for testing and estimating the contribution to the soil shear strength. Moreover, the standard procedures and apparatuses available in the public domain are regrettably suitable for testing of relatively stiffer materials. Therefore, conducting the tensile test of roots using off-the-shelf equipment often causes premature failure of the soft tissues and produces an erratic result, which ultimately leads to unrealistic soil shear strength. The experimental work replaced the traditional jaw type grips by innovative 3D-printed mold or metal ring with silicone, epoxy, and hot-glue to ensure a minimal degree of damage to the roots. Other scopes of the study include a comparison between fresh and refrigerated samples, the effect of sample storage temperature, $\mathrm{pH}$, and Optimum Effective Root Area (OERA) per unit area of soil. Initial study conducted on the Bermuda grass (Cynodon dactylon) roots involved comparison for different approaches based on the gripping technic to select the best method. Finally, the paper included the results of tensile strength test performed on Spartina alterniflora root samples following the suggested guidelines thus helping better evaluation of root embedded soil shear strength, enhancing the resistance against soil erosion, and conserving the ecosystem.
\end{abstract}

\section{Keywords}

Root Sampling, Root Tensile Strength, Soil Shear Strength, Soil Erosion Prevention, 
Protocol Development, Restore Ecosystem

\section{Introduction}

Studies show the existence of a strong correlation between the plant roots spread inside the subsoil area and shear strength of that soil. The higher tensile strength of roots contributes to thriving the soil shear strength and binding capacity, which prevents surface and subsurface soil erosion, a common occurrence especially in the wetland and coastal areas. Research shows that as per Louisiana's 2012 Coastal Master Plan, around 4548 square kilometer of land along the Louisiana coastal area is likely to erode over the next 50 years [1]. Construction of seawalls, which requires significant taxpayers' money, helped initially to control such erosion. Their installation, however, has resulted in several negative impacts, which forces coastal ecosystem managers to search for alternative environmental-friendly, sustainable solutions. One such solution is the cultivation of plants, and studies already show that plant roots' tensile strength directly improves soil shear strength, providing planting a clear advantage over constructed barriers.

Different studies revealed that vegetation roots often spread network and anchor in soil layer that potentially contributes to increasing the soil shear strength, improve slope stability, and arrest sliding of soil [2] [3] [4] [5]. Research works show that roots enhance mechanical reinforcement, e.g. shear strength of soil and the ties with root failure mechanism [6] [7] [8] [9]. Root density also influences the soil strength [10] [11] [12]. Current research shows that the tensile capacity of plant roots provides mechanical reinforcement to fine-grained soils at shallow depth and has the potential to increase shear strength ability [3] [13] [14]. Thus, vegetation roots play a significant role in improving soil slope stability by supporting the prevention of mass soil sliding and erosion [15]. The effect of root reinforcement on the soil slope stability can be evaluated directly regarding the additional shear strength provided by roots in root-reinforced soils, and this shear strength is a function of the tensile strength capacity of individual root samples [16]. A study on shear strength evaluation of an erosional soil system at the Fourchon Beach, Louisiana showed that soil shear strength value(s) was $56 \mathrm{kPa}$ for the lightly vegetated zone near the entrance to the Fourchon Beach, while the highest value was around $93 \mathrm{kPa}$ for the vegetated intertidal beach zone [17]. Different studies included evaluation of roots' contribution to soil shear strength based on the in-situ root pull-out test, tensile test, and shear test of recreated soil blocks reinforced with roots using the direct shear equipment [18]. However, physical properties such as diameter and number of root per unit area have an impact on the shear strength. In addition to those, soil moisture content and grain size also likely to impact the in-situ pullout test results. The ambient conditions such as tempera- 
ture, $\mathrm{pH}$, and humidity can affect the in-situ strength as well [19].

Furthermore, the onsite experimental test setups are highly time-consuming and as a result are very expensive too. Therefore, the collection of substantial numbers of in-situ soil root bonding strength (SRBS) data for predicting the SRBS behavior in a wetland and coastal area is almost impossible. On the contrary, the tensile testing of individual root samples and shear testing of recreated soil blocks in a laboratory-controlled environment are easily reproducible and require less investment of resources that make these approaches more popular among the scientific society. However, during the tensile testing, single root samples may get squeezed by the tensile grip and break prematurely. This premature breaking has the potential to produce significantly low and unrealistic tensile strength data and thus, result in a wrongly calculated soil shear strength value [20].

This paper describes the development of a novel gripping method to ensure zero effect of the gripping technique on the root samples at the support during the tensile testing. The authors established the process based on the performance evaluation of four different trial approaches (namely Method-I, II, III, and IV) of tensile testing performed on Bermuda grass (Cynodon dactylon) root samples collected locally at Ruston, Louisiana, USA. The approaches include replacing the traditional tensile testing grips usually made of metal or plastic with silicone and epoxy based grips for holding to the test specimens. As parallel work, the study also focused on the tensile strength of freshly collected and refrigerated root samples to better understand the effect of aging and refrigeration on the samples. Next, the authors tested the collected Spartina alterniflora roots from a marsh area in southern Louisiana, USA and compared the results. However, the study on the Spartina alterniflora included only tensile testing of aged samples. Finally, the paper proposed a preliminary guideline for storing, conditioning, and testing of root samples for better evaluation of root embedded soil strength at the wetland and coastal areas.

\section{Theoretical Background}

Subsurface parts of vegetation consist of rhizome and primary roots. Rhizomes of are short internodes, forming a dense underground horizontal mat where roots are branched out from the rhizome at almost normal direction as shown in Figure 1. Therefore, in most occasions, the probability of roots crossing a specified slip surface and acting as shear reinforcement was found to be higher in comparison to the rhizomes (see Figure 2).

Vegetation root has already been recognized as a factor useful for increasing the shear resistance of soil on an unstable slope and thus contribute to preventing soil erosion [21] [22] [23]. The significant factors that influence the shear resistance of root-permeated soil are the quantity and directional distribution of roots as well as their tensile strength, soil shear strength, and soil-root interaction [6] [7] [24]. The presence of roots increases soil shear strength based on the 


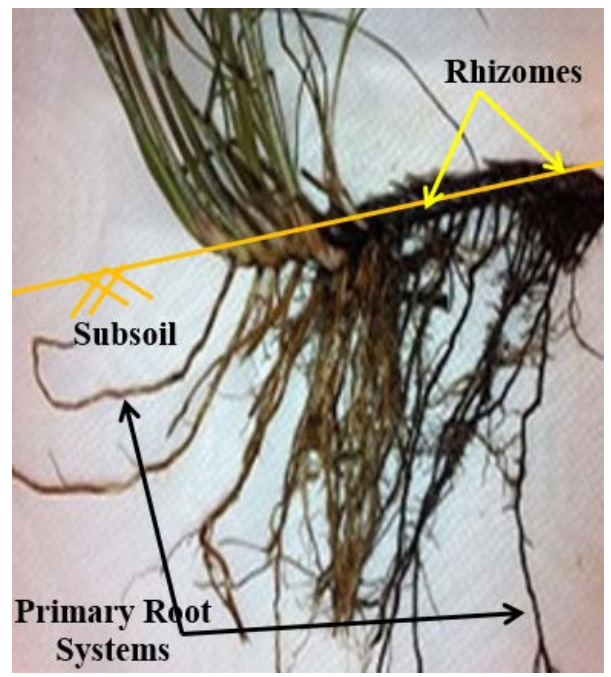

Figure 1. Primary root systems and rhizome in Bermuda grass (Cynodon dactylon).

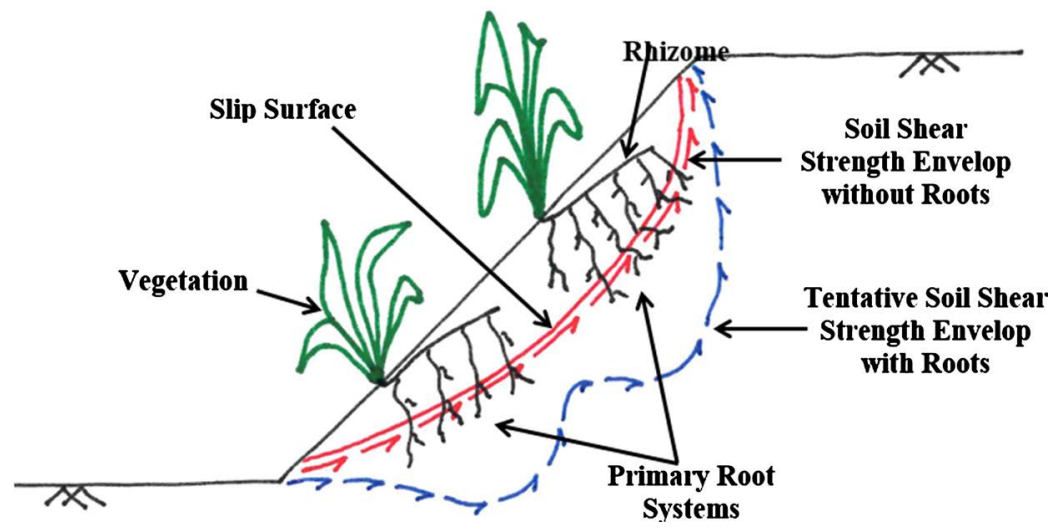

Figure 2. Schematic view of primary root system crossing the slip surface controlling soil erosion (after [27]).

postulation of roots growing vertically downward act as shear reinforcement and loaded piles [20].

A review work revealed the significant contribution of different authors for evaluating the relation between the tensile strength of root and shear strength of soil [18]. The tensile force is exerted on the roots as the soil sheared, indicating more roots less shear failure probability that was also shown by [25] and [26]. Increased shear strength for rooted soil is a function of additional cohesion [20]. The increased shear strength can be written as,

$$
s_{r}=s+C_{r}
$$

where $s_{r}$ is rooted soil shear strength, $s$ stands for shear strength of soils without roots, and $C_{r}$ is the increased shear strength due to the presence of roots and the equation for $C_{r}$ as

$$
C_{r}=t_{r}(\sin \theta+\cos \theta \tan \Phi)
$$

The value of $(\sin \theta+\cos \theta \tan \Phi)$ to be around 1.2 (assuming $\theta=45^{\circ}$ and $\Phi=$ $34^{\circ}$ ) for the most practical situation [20] and therefore, the Equation (2) rewrites 


$$
C_{r}=1.2 t_{r}
$$

Now, $t_{r}$, which is the total root strength per unit area becomes

$$
t_{r}=\frac{\sum T a}{A}
$$

where $T$ stands for tensile strength and $a$ is the cross-sectional area of a single root specimen. Here, $A$ is the accumulated area of all roots in the soil mass. As the study did not include any soil mass, therefore, the value of A is assumed 1 for simplicity in the calculation. In the end, after combining Equations (1)-(4) the equation for $s_{r}$ for each root is

$$
s_{r}=s+1.2 \sum T a
$$

Other studies also showed that the tensile strength data obtained from pullout tests might only have a local value that does not consider the spatial variations in vegetation and differences of ambient environment condition in the season when the test was carried out [28] [29] [30] [31]. Laboratory root tensile tests potentially provide data on root strength of a single specimen [32] [33] [34]. Previous studies showed linear and exponential relationships exist between the tensile force and root diameter [34] [35]. The study indicated that the laboratory tensile force required to break a root of a certain size is always higher than the in-situ root pullout resistance, possibly due to the complete different gripping mechanism [34]. However, the current study showed that increasing number of roots per unit area does not necessarily increase the soil shear strength and high root area to soil area ratio (RATSAR) may induce a sudden drop in soil shear strength.

Although study that root strength is not affected by storage and the various storing methods for storage time up to a few weeks for woody roots [36], the present study showed that the concept is difficult to apply when storing roots that mainly grow in wetland and coastal areas. Therefore, testing of samples needs to be carried out preferably on the same day or at least within a week [36]. A different study showed that the storage and handling of a root once collected is vital because of significant weakening after root death due to cellulose degradation [37]. Cellulose contents have a substantial impact on the tensile strength capacities of roots and moisture is one of the dominant controlling factors of tree root strain and strength [24] [38]. Suggestions by researchers showed root preservation technique maintain root strength after sampling and before testing [36] [37].

The current study concentrated mainly on the tensile strength evaluation of roots and the likelihood of any non-linear relation between soil shear strength and tensile strength in the contributed soil area. The study also focused on the soil $\mathrm{pH}$, temperature, and moisture content (humidity) plus root storage mechanism during transportation. 


\section{Tensile Testing Methods of the Root Samples}

Abundance in the availability of the Bermuda grass (Cynodon dactylon) in Ruston, Louisiana played as the critical factor in selecting this species for tensile testing of its roots. The researchers brought the carefully collected samples to the lab and washed the loose soil by spraying with ambient temperature $25^{\circ} \mathrm{C} \pm$ $1.11^{\circ} \mathrm{C}$ clean water and later refrigerated at $1.11^{\circ} \mathrm{C}$. The diameters of the root samples were between $1.60 \mathrm{~mm}$ and $3.18 \mathrm{~mm}$. Before the test, $76.2 \mathrm{~mm}$ long specimens were prepared by placing the samples on a cutting board and trimming any small root branches on both sides using a sharp scalpel. The relative humidity of the lab was $50 \% \pm 5 \%$. Next, the authors tested the samples by pulling at $2.54 \mathrm{~mm} / \mathrm{min}$ using the servo controlled tensile testing machine equipped with a load cell $(222 \mathrm{~N})$ sensitive up to second decimal places. The research work revealed that grips often squeeze the live root samples, which constitutes of hollow tube-like structure inside and ultimately affect the tensile strength of the samples. The study focused on four different gripping methods for the evaluation of the tensile testing procedure of the specimens.

\subsection{Method-I: Pulling of Bare Specimens}

In this method, the bare root samples were held inside the pneumatic grips and pulled. Roots were cut first and later clamped on both ends using the pneumatic grips attached to the pulling head of the tensile testing equipment as shown in Figure 3. In most of the cases, the grass root samples failed prematurely due to rupture at the grip indicating the method is not suitable for small diameter roots that usually grow in wetland and coastal regions. Although the grass root samples failed prematurely, this method may be highly suitable for tensile testing of bigger diameter strong roots and minimum needed preparation work ensures low disturbance on the large diameter root samples subjected for testing.

\subsection{Method-II: Pulling of Epoxy Covered Specimens}

In the Method-II, before testing, the roots were cut and placed inside $25.4 \mathrm{~mm}$ long polypropylene plastic straw, which were then filled with an off-the-shelf one-minute cure two parts epoxy resin and hardener system. After the epoxy

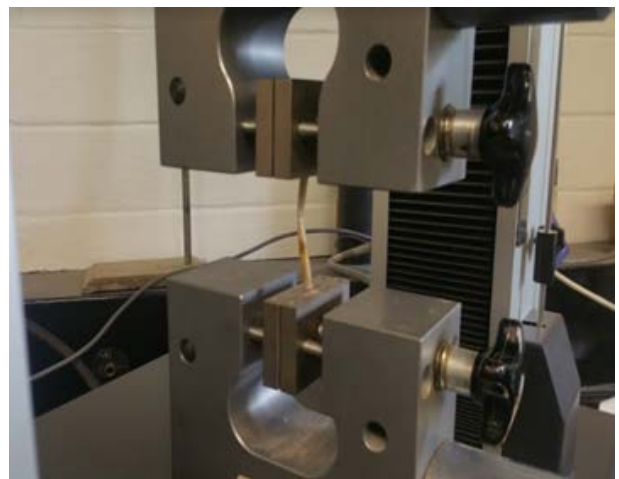

Figure 3. Testing of a bare root sample held by the grips (Method-I). 
resin is cured to form a hard structure around the sample, the samples are placed inside the pneumatic grip and pulled. However, in most of the cases, the ends still got pressed and were failing prematurely due to rupture of the sample at the grip or the epoxy-sample joint location. Although the procedure (see Figure 4) produced scattered better result in comparison to the Method-I, the method also seemed to be not appropriate for small diameter roots due to the reasons of substantially greater sample preparation time and more probability of compromised samples during the preparation process.

\subsection{Method-III: Pulling Using 3D Printed Mold}

The Method-III utilized a pair (one for the top and one for bottom grip in the tensile testing equipment) of 3D printed two parts mold as shown in Figure 5. The inner dimension of each part was $25.4 \mathrm{~mm} \times 25.4 \mathrm{~mm}$ and had a relatively deep cavity due to the $6.35 \mathrm{~mm}$ thick wall printed all around. One of the walls had a $3.175 \mathrm{~mm}$ diameter half-circle to allow a passage for the root samples. Before the root sample had been positioned on the half circle, WD40 was sprayed in the cavity of both parts. The roots were then placed on the half circle and filled the crater with an off-the-shelf five minutes epoxy up to the bottom of the half circle. Once the epoxy got cured, and the sample was in place, the other

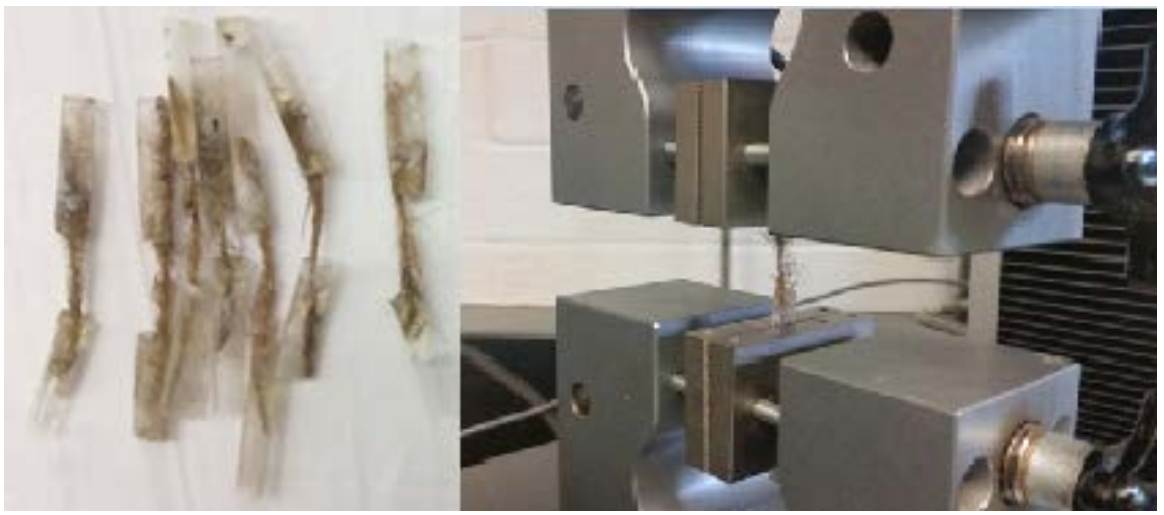

Figure 4. Testing of samples covered with epoxy at the end (Method-II).

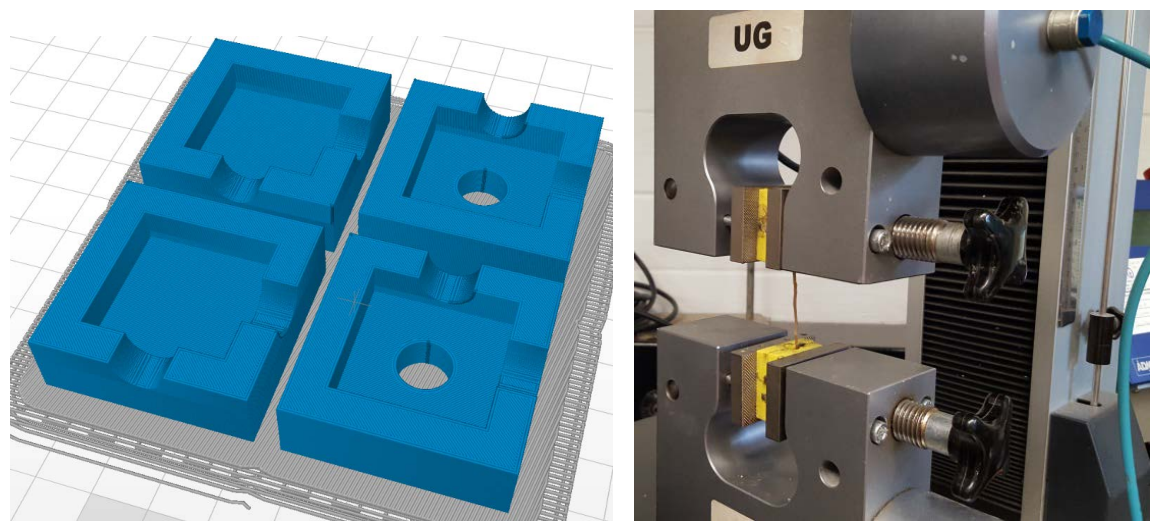

Figure 5. 3D printed mold (Yellow Component) holding the sample inside the pneumatic grip (Method-III). 
component was positioned on the top, and injected the inside of the cavity with resin. Once the resin got cured, the 3D molds along with the sample were placed inside the pneumatic grip connected to the tensile testing equipment and pulled. The tensile strength results obtained was found better and consistent in comparison to the previous two methods. However, the sample preparation procedure was very cumbersome. Moreover, the pneumatic grips were too strong and squeezed the 3D molds resulted into replacement between testing of every 12 to 15 samples. Therefore, although the Method-III produced a better result, substantial time and resources involved in 3D printing was the principal drawback and forced to search for further smart, easily doable approach.

\subsection{Method-IV: Modified Swivel Hook System}

The Method-IV mainly based on a fabricated sample holding system made of quick-link, modified double-swivel, and S-binder for each end. Modification of the double-swivel included the elimination of the middle bolt part leaving the two shackles with a hole on the flat side of each of them. The locking clip on one side of the S-binder was removed to ensure secure attachment of the shackle and the quick-connector system to the pneumatic grip of the tensile testing equipment. This setup guaranteed innocuous testing of the root samples. First, the two S-binders were attached, one at the top and the other at the bottom fixture of the tensile testing equipment. Next, after connecting a quick-link, one side of the hollow part of the shackle was covered forming a bin with a piece of masking tape and placed on a cooking grade wax paper. Later, a root sample was slid up to $25.4 \mathrm{~mm}$ inside the hole located on the flat side of the shackle. Finally, pouring of one-minute epoxy in the shackle hole above the masking tape bin confirms holding of the root sample once the epoxy got cured. Next, the shackle was attached to the open end of the S-binder, and the specimens were then pulled to obtain the tensile strength.

\subsection{Method-IVEx: Modified Swivel Hook System with Hot Glue}

The Method-IVEx has the same preparatory steps as Method-IV with an exception of using of (see Figure 6) hot glue instead of epoxy. The method produced
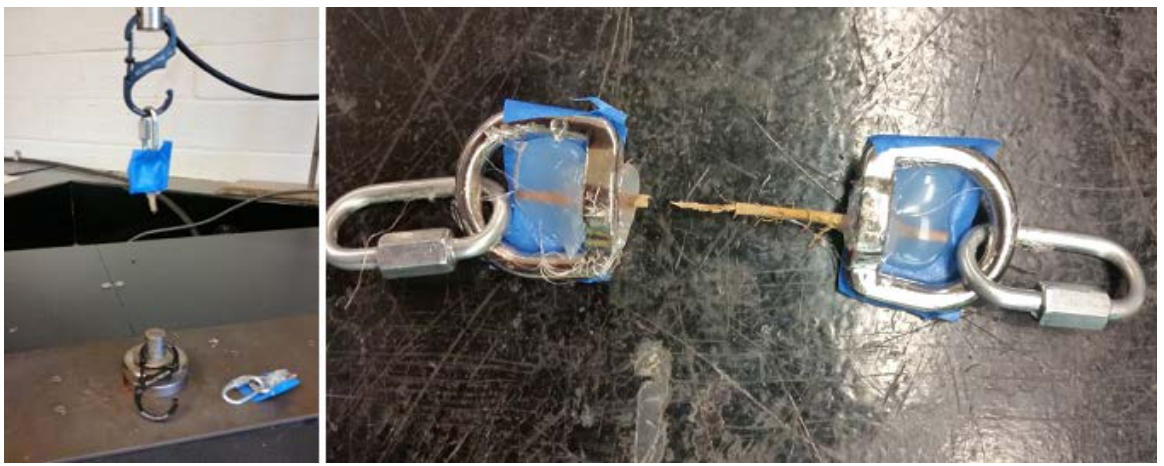

Figure 6. Ruptured sample after the tensile testing using Method-IV (left) and Method-IVEx (right). 
promising result as Method-IV, while instant availability of hot glue made the method more attractive to the research study.

\subsection{Initial Results and Method Selection}

For each method, 20 samples were tested, and the percent coefficient of variation $(\mathrm{CoV})$ was calculated by dividing the standard deviation with the mean value and shown in Figure 7. Method-I have the highest $\mathrm{CoV}$ value indicating intermittent failure of the bare root specimens due to squeezing and probably shear action at the grips producing inconsistent results. These failures observed were mostly at the top grip that could occur due to the presence of the rough surface (checkered pattern) on the inner holding plane of the grip. However, as the samples failed prematurely, the authors did not feel any further investigation of the reason for such rapture array. The CoV value obtained in Method-II is better in comparison to Method-I. However, sample preparation procedure enforces significant waiting time before actual testing of the specimens, and inconsistent results were still noticeable even after careful preparation of the samples. In $\mathrm{Me}$ thod-III samples were encapsulated and glued inside a 3D printed mold and observed a significant improvement on the CoV value. Although the Method-III established the zero impact of direct gripping on the bare samples in comparison to the Method I and II, the process was too complicated for a full-scale continuation of the testing. Therefore, the Method-III was abandoned. Method-IV and Method-IVEx (minor modification in Method-IV) produced the most consistent tensile breaking strength of the roots with a minimum investment of time and resources. The associated lowest $\mathrm{CoV}$ values also supported the outcome.

The lowest $\mathrm{CoV}$ value was an indication of the minimum variation due to the

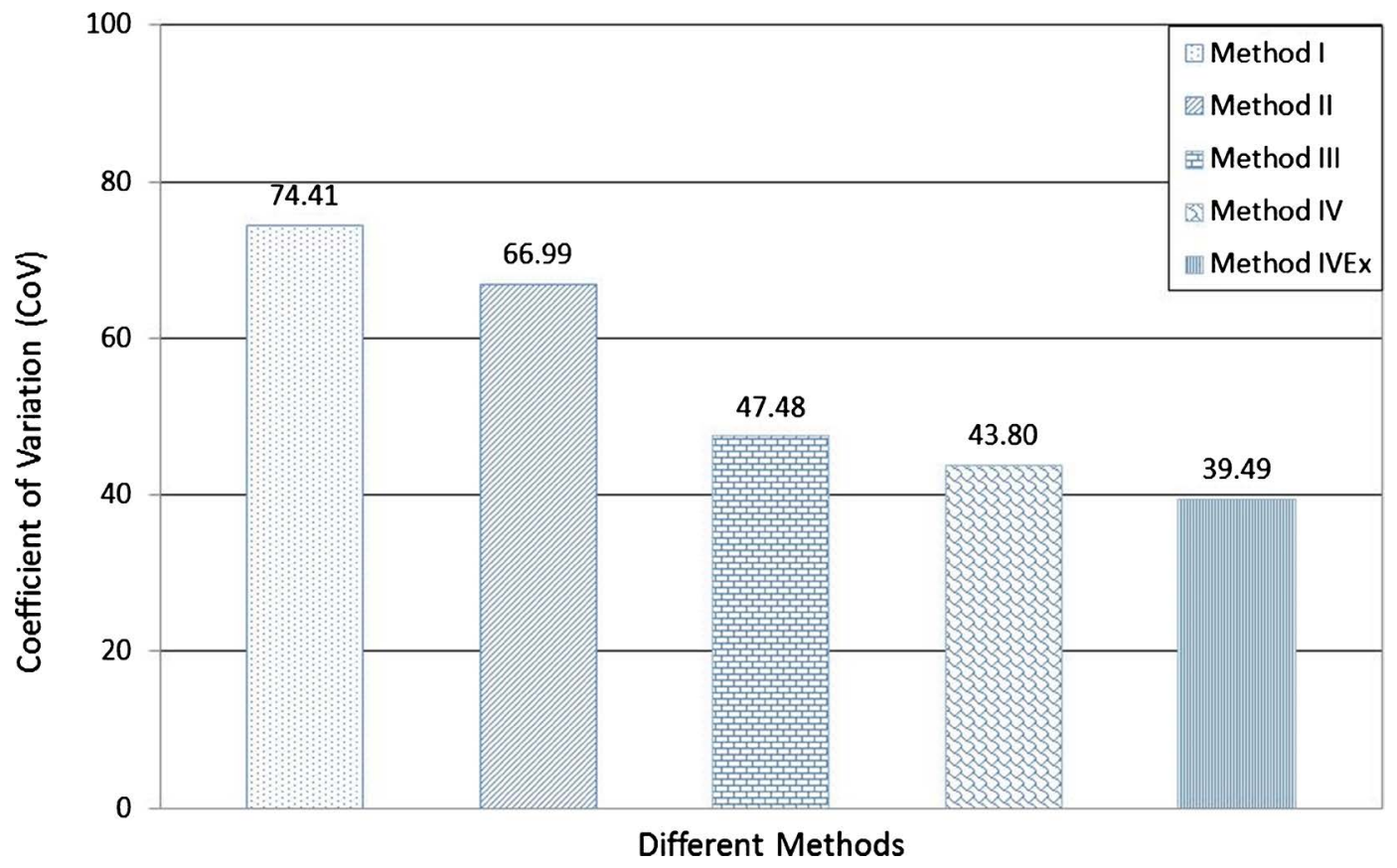

Figure 7. CoV of tensile strength based on different gripping technique. 
sample preparation procedure. Therefore, based on the outcome from the method selection procedure and easy, economical availability of hot-glue plus other accessories the researchers continued with the Method-IVEx to the next phase for evaluation of any aging, temperature, and $\mathrm{pH}$ effect on the samples. Changes of $\mathrm{pH}$ in the root could occur regarding the bulk soil [19]. Before the collection of the sample, soil $\mathrm{pH}$ and temperature was measured using a handheld 3-way meter. The soil $\mathrm{pH}$, moisture content, and temperature were recorded at 6.8 , $65 \%$, and $22.2^{\circ} \mathrm{C}$ respectively.

In contrast to the traditional way of storing in a refrigerator at $1.11^{\circ} \mathrm{C}$, the authors kept the collected samples inside a humidor where the temperature was between $20^{\circ} \mathrm{C}$ and $21.1^{\circ} \mathrm{C}$ matching the ambient temperature. Once brought into the lab, removal of all the dirt and soils from the samples took place by carefully spraying fresh ambient temperature water that has a $\mathrm{pH}$ of $6.7-6.9$. Next, 20 samples (Set-I) were conditioned in a humidor for one hour at $20^{\circ} \mathrm{C}-21.1^{\circ} \mathrm{C}$, and 40 samples were refrigerated at $1.1^{\circ} \mathrm{C}$ to $4.4^{\circ} \mathrm{C}$. The research planned included testing of 20 refrigerated samples (Set-II) on the same day as Set-I after refrigeration and conditioning for six hours and one hour respectively. The researchers refrigerated the rest 20 samples (Set-III) at $1.1^{\circ} \mathrm{C}$ to $4.4^{\circ} \mathrm{C}$ for seven days before conditioning and testing.

Figures 8-10 show the diameter and analyzed results of tensile tests performed on the individual root samples. The average diameter of the Set-I, II, and III specimens are $2.52 \mathrm{~mm}, 2.37 \mathrm{~mm}$, and $2.49 \mathrm{~mm}$ respectively. The Set-I samples collected, not refrigerated, conditioned, and tested on the same day produced

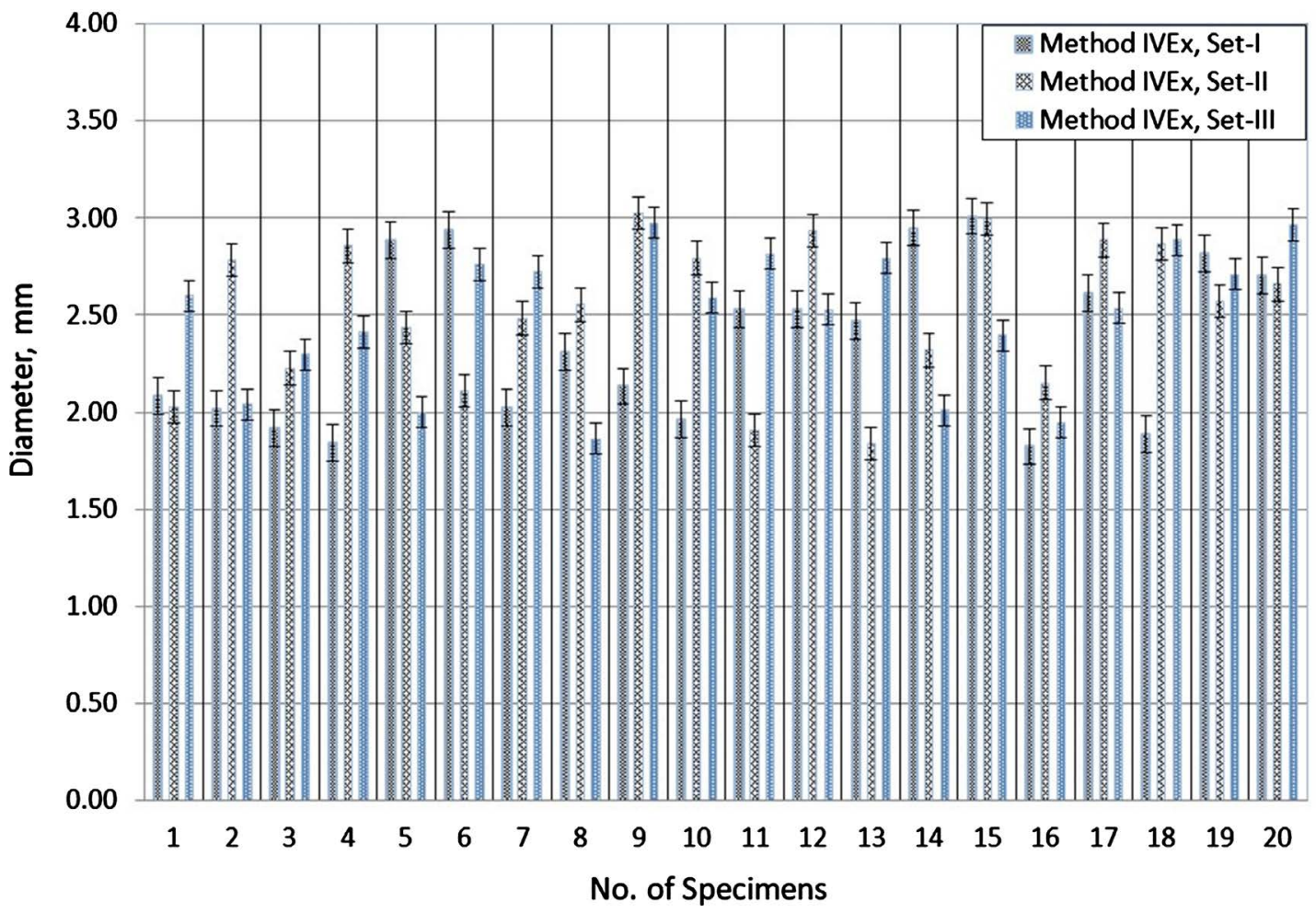

Figure 8. Diameter of individual root samples. 


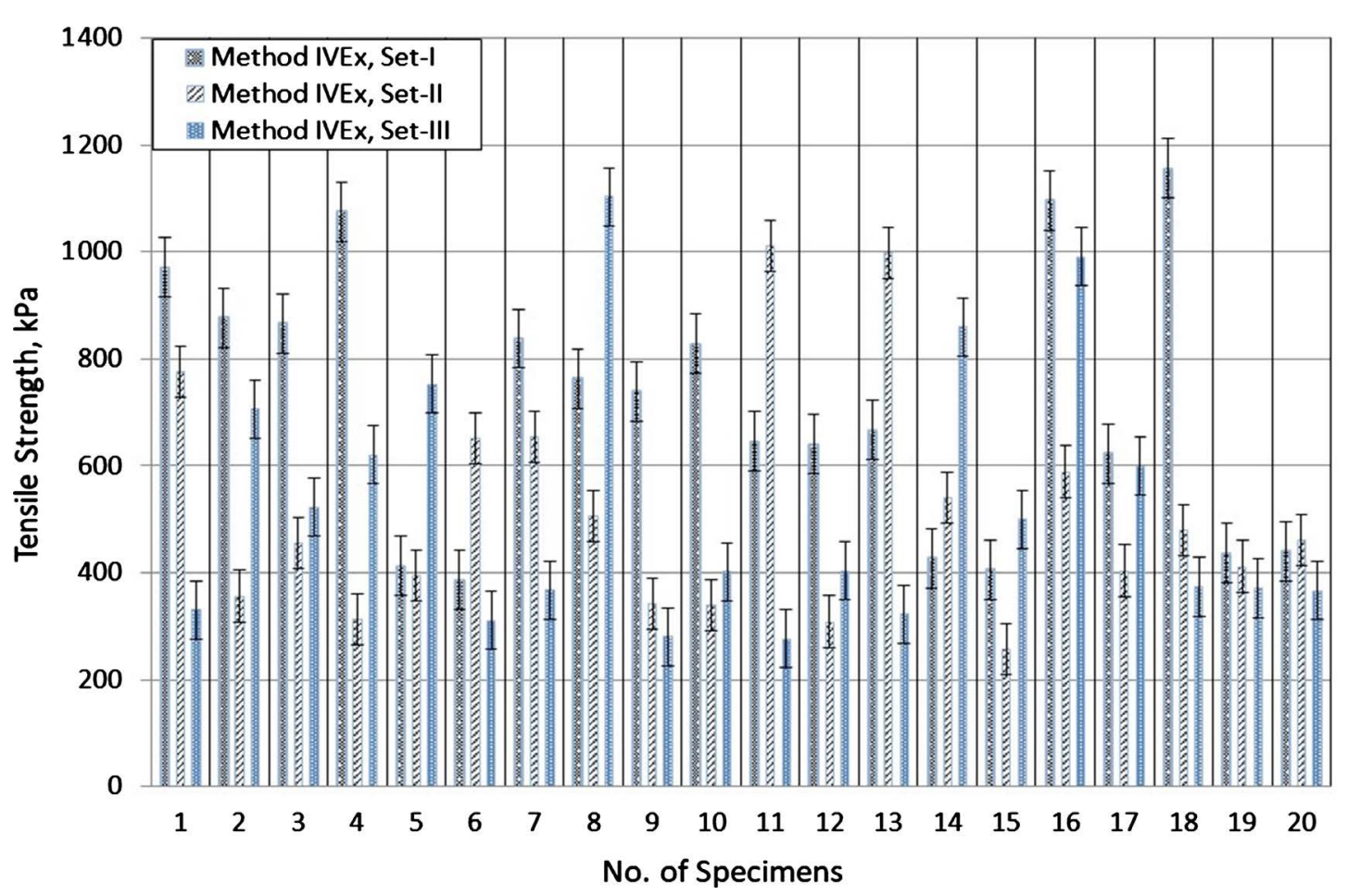

Figure 9. Tensile strength of individual root samples.

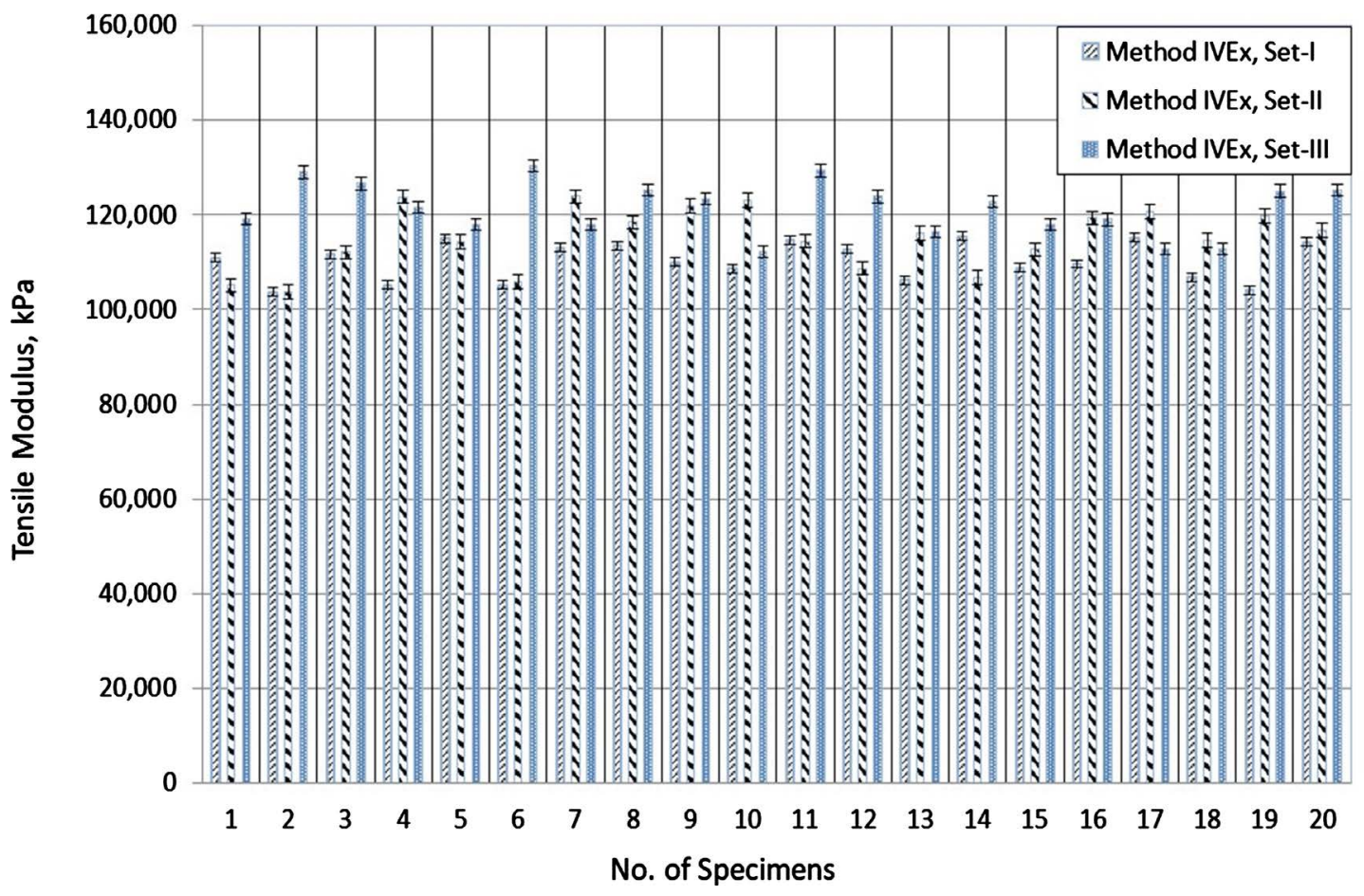

Figure 10. Tensile modulus of individual root samples.

average tensile strength of $737.73 \mathrm{kPa}$, around $12.0 \%$ and $12.5 \%$ higher than that of the Set-II and III samples. The CoV value was found around $15 \%$ to $21 \%$ higher for Set-I in comparison to Set-II and Set-III, which indicated a more comprehensive range between the maximum and minimum tensile strength 
values. The root samples were too weak to hold an extensometer. Therefore, strains on the samples were calculated by dividing the final displacement at the break obtained from the traveling of the actuator by the actual distance (38.1 $\mathrm{mm}$ ) between the grips holding the samples. The research work found the average tensile modulus for the Set-I samples around 111,350.4 kPa that was about $3.50 \%$ and $8.40 \%$ lower than those of Set-II and Set-III. The lower tensile modulus value indicated that Set-I samples were more ductile and resilient in comparison to Set-II and III samples. Hot glue poured inside the loop on the Set-II and Set-III samples may cause some thermal effect, which possibly was responsible for the lower tensile strength and higher tensile modulus when compared to the Set-I samples. In the case of Set-III samples, average lowest tensile strength, and highest tensile modulus further indicated a possible effect of root specimens storing practice and aging on the roots.

Reviewing different literature [18] [36] [37] and after completion of the tensile strength tests and conducting the study, the researcher felt to have a consistent methodology for tensile testing of root samples and evaluating their contribution to soil shear strength. The authors developed the tensile testing methodology after the evaluation of the experimentation performed on the Bermuda grass $\left(\mathrm{CH}^{-}\right.$ nodon dactylon) roots. The current study showed that the sample preparation procedure has a substantial impact on the tensile strength of root specimens. Based on the tensile test results obtained by evaluating the developed technique (Method-IV and Method-IVEx), the authors outlined a practice for sample preparation and testing procedure.

\section{Suggested Testing Protocol}

The investigation showed that protocols for collection and storing of the samples had pronounced effect on the tensile strength. The following steps were found to be helpful during the testing and evaluation study.

- Measure the $\mathrm{pH}$, moisture content, and temperature of the soil at the site.

- Carefully collect soil with root samples using a soil sampler or handheld/electric sod cutter.

- Store the samples in a humidor or controlled environment container and seal it. However, the specimens need refrigeration if they require substantial travel time (more than half an hour) to the laboratory.

- After bringing the samples the lab, wash away the dirt from the samples by pouring fresh water of same $\mathrm{pH}$ and temperature.

- Refrigerate the samples if not tested on the same day. The study revealed the mandatory conditioning of refrigerated samples before testing produces better results in comparison to the un-conditioned samples.

The current study showed that the systematic preparation of the sample produced reliable tensile strength data. Based on the research works, the paper proposes the following steps for preparing the test setup.

- Connect the S-binder to the pulling head of the tensile testing equipment. 
- Cut the sample at $76.2 \mathrm{~mm}$ length using a scalpel.

- Carefully trim $5.95 \mathrm{~mm}$ or longer side branches without harming the sample to be tested.

- Measure the diameter of the root sample at different locations across the length using a sophisticated slide caliper or a screw gauge and calculate the average diameter.

- Slide each end of the root sample through the hole on each Part-A1 and Part-A2 so that $1 / 2$ inch length of the specimen is visible inside the loop.

- Pour hot-melt adhesive that has ethylene-vinyl acetate (EVA) copolymers (hot glue) or epoxy resin applicable in the moist environment inside the loop of Part A1 and A2.

- Once the hot glue or epoxy cured for the mentioned designated period, attach the setup to the open end of the S-binder.

- The jogging rate of the machine needs to be low (between $0.254 \mathrm{~mm} / \mathrm{min}$ $1.25 \mathrm{~mm} / \mathrm{min}$ ) to produce enough tension (up to around $0.22 \mathrm{~N}$ to $2.22 \mathrm{~N}$ ) as well as to ensure no premature rip causing tension force on the specimen.

- Next, pull the specimens slowly at $1.25 \mathrm{~mm} / \mathrm{min}$.

- Record and report the peak tensile strength of the samples.

\section{Tensile Testing of Spartina alterniflora and Results}

Salt marsh cordgrass (Spartina alterniflora Loisel) has been used increasingly to restore or construct estuarine wetland habitat [39] and reduce shoreline erosion [40]. This leads the author to test on Spartina alterniflora samples and the authors were able to collect limited numbers of samples from the coastal region of Louisiana, brought to the lab, and categorized them as R1, R2, and R3 based on their diameters. The average diameters for R1, R2, and R3 were $3.8 \mathrm{~mm}, 2.0 \mathrm{~mm}$, and $0.76 \mathrm{~mm}$ respectively. The RATSAR calculated based on the average diameter of each of root type produced the mean tensile strength of $950.1 \mathrm{kPa}, 1025.3$ $\mathrm{kPa}$, and $2173.2 \mathrm{kPa}$ for root types $\mathrm{R} 1, \mathrm{R} 2$, and $\mathrm{R} 3$ respectively (see Table 1 ). The higher tensile strength value of R3 was possibly due to its very low cross-section that tore short after the tensile test started. However, this high tensile strength has the potential to mislead the rooted soil shear strength calculation, and therefore, the further study requires before reaching any conclusion.

Using the Method-IVEx Set-I tensile test data and Equation (5) the researchers calculated the increase in soil shear strength assuming four roots of per $645.16 \mathrm{~mm}^{2}$ area of soil. The soil shear strength values increase in rooted soil by around $28 \%$ in comparison to the unrooted soil sample (see Figure 11).

The applied normal stress of 4.4, 22.3, 29.3, 49.2, 89.2, 112.6, 131.8, and 155.1 $\mathrm{kPa}$, along with the shear rate of $1.25 \mathrm{~mm} /$ min produced shear strength of 19.9, $38.7,52.0,63.5,80.1,99.6,109.8$ and $128.1 \mathrm{kPa}$ respectively on the samples. The regression equation developed based on these values produced the corresponding soil cohesion $(C)$ and friction angle $(\phi)$ for non-rooted soil samples as 24.94 $\mathrm{kPa}$ and $33.42^{\circ}$. 
Table 1. Peak load and averaged tensile strength of Spartina alterniflora.

\begin{tabular}{|c|c|c|c|c|}
\hline & & & & \\
\hline Root type & Sample ID & Peak Load (N) & Tensile Strength $(\mathrm{kPa})$ & Avg. Tensile Strength $(\mathrm{kPa})$ \\
\hline \multirow{3}{*}{$\mathrm{R} 1$} & R11 & 42.66 & & \multirow{3}{*}{2244} \\
\hline & $\mathrm{R} 12$ & 39.72 & 2598 & \\
\hline & $\mathrm{R} 13$ & 28.16 & 1715 & \\
\hline \multirow{6}{*}{ R2 } & $\mathrm{R} 21$ & 16.59 & 3274 & \multirow{6}{*}{2553} \\
\hline & R22 & 9.52 & 1878 & \\
\hline & $\mathrm{R} 23$ & 8.49 & 1676 & \\
\hline & R24 & 15.75 & 3107 & \\
\hline & $\mathrm{R} 25$ & 14.68 & 2896 & \\
\hline & R26 & 12.59 & 2484 & \\
\hline \multirow{6}{*}{ R3 } & R31 & 8.19 & 17,947 & \multirow{6}{*}{15,720} \\
\hline & R32 & 7.92 & 17,362 & \\
\hline & R33 & 7.07 & 15,509 & \\
\hline & R34 & 5.65 & 12,387 & \\
\hline & R35 & 5.43 & 11,899 & \\
\hline & R36 & 8.76 & 19,215 & \\
\hline
\end{tabular}

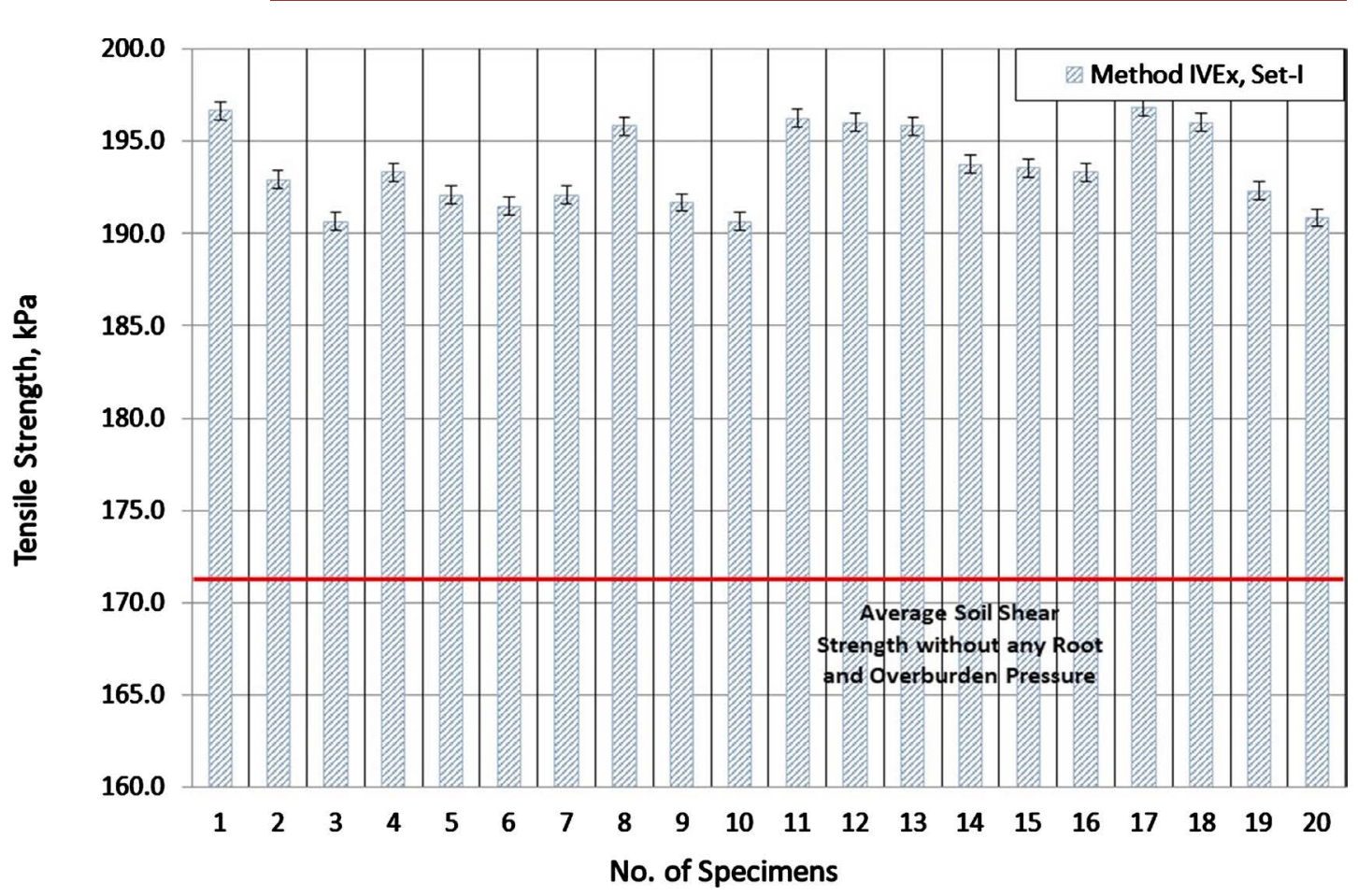

Figure 11. Contribution of roots towards the increase of soil shear strength.

The study also compared the outcome of the Equation (5) to the experimental evaluation. The authors manually planted Set-I roots with an average diameter of $2.45 \mathrm{~mm}$ (see Figure 12) inside the soil and conducted shear test following the similar normal pressure applied for testing the unrooted soil samples (see Table 2). 


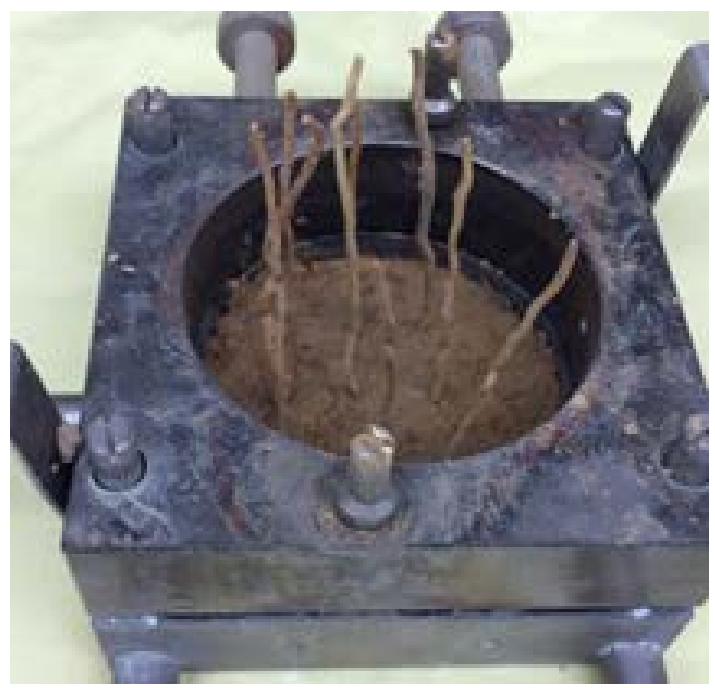

Figure 12. Manually planted root sample inside the shear box of direct shear test machine (after [27]).

Table 2. Planted no. of roots studied related to the corresponding normal stress.

\begin{tabular}{|c|c|c|c|c|c|c|c|c|}
\hline \multirow{3}{*}{$\begin{array}{c}\text { Normal } \\
\text { Stress, } \mathrm{kPa}\end{array}$} & \multirow{3}{*}{$\begin{array}{c}\text { Shear } \\
\text { Stress, } \mathrm{kPa}\end{array}$} & \multicolumn{7}{|c|}{ No. of Roots } \\
\hline & & 4 & 6 & 8 & 10 & 12 & 14 & 16 \\
\hline & & \multicolumn{7}{|c|}{ Area, $\mathrm{mm}^{2}$} \\
\hline 30.3 & 137.2 & 251.0 & 376.8 & 501.9 & 627.7 & 753.6 & 878.7 & 1004.5 \\
\hline 153.8 & 266.8 & 242.6 & 363.2 & 484.5 & 605.8 & 727.1 & 848.4 & 969.0 \\
\hline 202.0 & 358.5 & 252.9 & 379.4 & 505.8 & 632.3 & 758.7 & 885.2 & 1011.6 \\
\hline 339.2 & 437.8 & 244.5 & 366.5 & 489.0 & 611.0 & 732.9 & 855.5 & 977.4 \\
\hline 615.0 & 552.3 & 251.0 & 376.8 & 501.9 & 627.7 & 753.6 & 878.7 & 1004.5 \\
\hline 776.3 & 686.7 & 247.7 & 371.0 & 494.8 & 618.7 & 742.6 & 866.5 & 989.7 \\
\hline 908.7 & 757.0 & 252.9 & 380.0 & 506.5 & 632.9 & 759.4 & 885.8 & 1012.9 \\
\hline 1069.4 & 883.2 & 244.5 & 367.1 & 489.0 & 611.6 & 734.2 & 856.1 & 978.7 \\
\hline
\end{tabular}

Figure 13 shows the anticipated shear strength with increasing of root area when subjected to similar normal stress used for calculation of unrooted soil. As expected, the researchers observed the Equation (5) produced a linear relationship which did not conform to the actual shear test value of the rooted samples. It shows that the definite shear stresses of the rooted soil samples were increasing with increasing root area per unit area of soil up to a certain point and started reducing after that. After taking into account of all the shear stress scenarios, the authors found the maximum shear strength regime of rooted soil between $464.5 \mathrm{~mm}^{2}$ to $645.16 \mathrm{~mm}^{2}$ per $3167.74 \mathrm{~mm}^{2}$ of total area, which was calculated based on the $63.5 \mathrm{~mm}$ diameter of the soil shear box. The authors obtained the OERA value by dividing the cumulative root area with the soil box area and found the OERA ranging from around $14.5 \%$ to $20.5 \%$ that had potential to contribute to the maximum shear strength of the soil. 


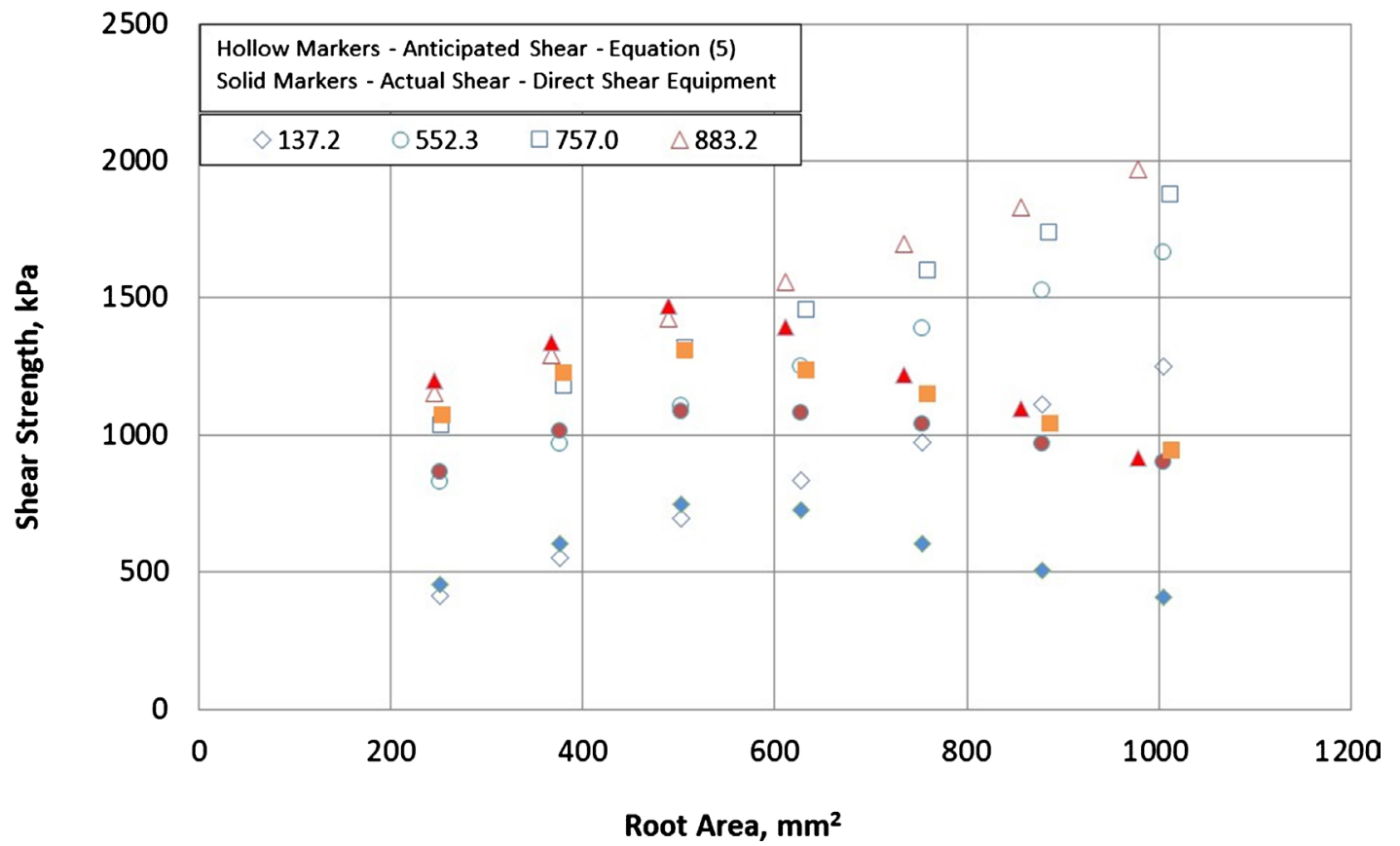

Figure 13. Variation in anticipated and actual shear strength with increasing number of roots.

\section{Discussion}

Vegetation growth is one of the solutions to enhance slope stability and prevent soil erosion, especially in coastal areas. The study comprising of experimental work was undertaken to evaluate the effect of plant roots' tensile strength on the shear strength of soil. The principal focus of the study included tensile strength evaluation procedure of roots. In addition to that, the investigation revealed soil $\mathrm{pH}$, temperature, moisture content, root storage mechanism, and aging might also impact the projected shear strength, which is often estimated using a linear mathematical relation. The researchers collected soil samples with and without roots of Bermuda grass (Cynodon dactylon) from Ruston, Louisiana. The tensile testing procedure was developed by testing and processing one hundred carefully selected root samples, and finally, the Method-IVEx was selected. Next, the Method-IVEx implemented on the limited numbers of Spartina alterniflora root samples that grow in the coastal area of Louisiana. The testing of Spartina alterniflora root samples also produced admirable results. Finally, the direct shear tests were performed on the 56 soil samples by again embedding Bermuda grass (Cynodon dactylon) roots manually into them to study the effect of roots on soil shear strength. However, due to the limited number of samples, the direct shear test was not performed on soil samples with Spartina alterniflora root.

The study shows the possible existence of a non-linear (perhaps parabolic) relation between the tensile strength of roots and soil shear strength in the contributed area. The finding was contradictory to the Equation (5) and therefore, requires further studies. Another outcome of the current investigation was the importance of the consideration of the uneven distribution of roots in the sub-soil area that traditional testing approaches are restrained to cover. 


\section{Conclusions}

The study achieved its objectives showing the influence of roots' sampling and testing procedure for better estimation of soil shear strength. The outcome of the study shows that the tensile strength of roots increases the shear strength of soil, thus prevents soil erosion and helps to conserve the ecosystem. However, as no standardized procedure for tensile testing of root samples is available in the public domain, there is a need of a standard procedure that will allow the researchers and coastal restoration engineers to avoid different routes and prevent leading to inconsistent soil shear strength evaluation. Thus, the novelty of the paper is laying the foundation for the development of a protocol for tensile strength evaluation of root samples and their contribution to soil shear strength.

Inspired by these findings, the author(s) proposed an in-situ root testing equipment suitable for vegetation grow in the coastal areas and awarded with the initial proof-of-concept fund from the Louisiana Board of Regents.

\section{Acknowledgements}

Sincere gratitude goes to the proposal review committee for their constructive criticism, various thoughtful inputs. Special thanks go to the undergraduate Mechanical Engineering student Joey Higuera for fabricating the 3D molds.

\section{Conflicts of Interest}

The authors declare no conflicts of interest regarding the publication of this paper.

\section{References}

[1] Louisiana's 2012 Coastal Master Plan. Coastal Protection and Restoration: The 2012 Master Plan and the RESTORE Act.

[2] Matteo, T. (2006) Root Tensile Strength Relationships and Their Slope Stability Implications of Three Shrub Species in the Northern Apennines (Italy). Geomorphology, 87, 268-283.

[3] O’Loughlin, C. (1974) The Effect of Timber Removal on the Stability of Forest Soils. Hydrology, 13, 121-134.

[4] Stokes, A., Atger, C., Bengough, A.G., Fourcaud, T. and Sidle R.C. (2009) Desirable Plant Root Traits for Protecting Natural and Engineered Slopes against Landslides. Plant Soil, 324, 1-30. https://doi.org/10.1007/s11104-009-0159-y

[5] Comino, E. and Druetta, A. (2010) The Effect of Poaceae Roots on the Shear Strength of Soils in the Italian Alpine Environment. Soil Tillage Research, 106, 194-201. https://doi.org/10.1016/j.still.2009.11.006

[6] Comino, E., Marengo, P. and Rolli, V. (2010) Root Reinforcement Effect of Different Grass Species: A Comparison between Experimental and Models Results. Soil Tillage Research, 110, 60-68. https://doi.org/10.1016/j.still.2010.06.006

[7] Mickovski, S.B., Hallett, P.D., Bransby, M.F., Davies, M.C.R., Sonnenberg, R. and Bengough, A.G. (2009) Mechanical Reinforcement of Soil by Willow Roots: Impacts 
of Root Properties and Root Failure Mechanism. Soil Science Society of America, 73, 1276-1285. https://doi.org/10.2136/sssaj2008.0172

[8] Waldron, L.J. (1977) The Shear Resistance of Root-Permeated Homogeneous and Stratified Soil. Soil Science Society America Journal, 41, 843-849. https://doi.org/10.2136/sssaj1977.03615995004100050005x

[9] Waldron, L.J. and Dakessian, S. (1981) Soil Reinforcement by Roots. Soil Science, 132, 427-435. https://doi.org/10.1097/00010694-198112000-00007

[10] Stokes, A., Salin, F., Kokutse, A.D., Berthier, S., Jeannin, H., Mochan, S., Kokutse, N., Dorren, L., Abd. G.M. and Fourcaud, T. (2005) Mechanical Resistance of Different Tree Species to Rock Fall in the French Alps. Plant Soil, 278, 107-117. https://doi.org/10.1007/s11104-005-3899-3

[11] Wu, T.H. (1976) Investigation of Landslides on Prince of Wales Island, Alaska. Ohio State University, Report N5, 93.

[12] Loades, K., Bengough, A., Bransby, M. and Hallett, P. (2010) Planting Density Influence on Fibrous Root Reinforcement of Soils. Ecological Engineering, 36, 276-284. https://doi.org/10.1016/j.ecoleng.2009.02.005

[13] Shewbridge, S.E. and Sitar, N. (1989) Deformation Characteristics of Reinforced Sand in Direct Shear. Geotechnical Engineering, 115, 1134-1147. https://doi.org/10.1061/(ASCE)0733-9410(1989)115:8(1134)

[14] Skaugset, A. (1997) Modeling Root Reinforcement in Shallow Forest Soils. Ph.D. Dissertation, Oregon State University, Corvallis.

[15] Wu, T., Kokesh, C.M., Trenner, B.R. and Fox, P.J. (2014) Use of Live Poles for Stabilization of a Shallow Slope Failure. Journal of Geotechnical and Geoenvironmental Engineering, 140, 1-13. https://doi.org/10.1061/(ASCE)GT.1943-5606.0001161

[16] Fan, C.C. and Su, C.F. (2008) Role of Roots in the Shear Strength of Root-Reinforced Soils with High Moisture Content. Ecological Engineering, 33, 157-166. https://doi.org/10.1016/j.ecoleng.2008.02.013

[17] Boudreaux, J.P. (2012) Shear Strength Evaluation of an Erosional Soil System at Fourchon Beach. Louisiana State University, Baton Rouge.

[18] Giadrossich, F., Schwarz, M., Cohen, D., Cislaghi, A., Vergani, C., Hubble, T., Phillips, C. and Stokes, A. (2017). Methods to Measure the Mechanical Behaviour of Tree Roots: A Review. Ecological Engineering, 109, 256-271. https://doi.org/10.1016/j.ecoleng.2017.08.032

[19] Refat, A.Y. and Mitsuo, C. (1989) Root-Induced Changes in the Rhizosphere of Plants. I. pH Changes in Relation to the Bulk Soil. Soil Science and Plant Nutrition, 35, 461-468. https://doi.org/10.1080/00380768.1989.10434779

[20] Wu, T.H., McKinnel, W.P. and Swanston, D.N. (1979) Strength of Tree Roots, Landslides on Prince of Wales Island, Alaska. Canadian Geotechnical Journal, 16, 19-33. https://doi.org/10.1139/t79-003

[21] Anderson, M.G. and Richards, K.S. (1987) Slope Stability: Geotechnical Engineering and Geomorphology. Wiley, Chichester, 585.

[22] Coppin, N.J. and Richards, I.G. (1990) Use of Vegetation in Civil Engineering. Butterworth, London, 272.

[23] Operstein, V. and Frydman, S. (2000) The Influence of Vegetation on Soil Strength. Ground Improvement, 4, 81-89. https://doi.org/10.1680/grim.2000.4.2.81

[24] Genet, M., Stokes, A., Salin, F., Mickovski, S.B., Fourcaud, T., Dumail J. and Beek, R. (2005) The Influence of Cellulose Content on Tensile Strength in Tree Roots. Plant and Soil, 278, 1-9. https://doi.org/10.1007/s11104-005-8768-6 
[25] De Baets, S., Poesen, J., Reubens, B., Wemans, K., De Baerdemaeker, J. and Muys, B. (2008) Root Tensile Strength and Root Distribution of Typical Mediterranean Plant Species and Their Contribution to Soil Shear Strength. Plant Soil, 305, 207-226. https://doi.org/10.1007/s11104-008-9553-0

[26] Schwarz, M., Preti, F., Giadrossich, F., Lehmann, P. and Or, D. (2010) Quantifying the Role of Vegetation in Slope Stability: A Case Study in Tuscany (Italy). Ecological Engineering, 36, 285-291. https://doi.org/10.1016/j.ecoleng.2009.06.014

[27] Minhaz, M.S., Jay, X.W., Shaurav, A. and William, B.P. (2016) Soil-Binding Ability of Vegetation Roots in Enhancing Erosion Resistance of a Shallow Slope. International Journal of Geotechnical Engineering, 10, 409-417. https://doi.org/10.1080/19386362.2016.1168608

[28] Burroughs, E.R. Jr. and Thomas, B.R. (1977) Declining Root Strength in Douglas-Fir after Felling as a Factor in Slope Stability. USDA Forest Service Research Paper 190, 27 p.

[29] Schmidt, K.M., Roering, J.J., Stock, J.D., Dietrich, W.E., Montgomery, D.R. and Schaub, T. (2001) The Variability of Root Cohesion as an Influence on Shallow Landslide Susceptibility in the Oregon Coast Range. Canadian Geotechnical Journal, 38, 995-1024. https://doi.org/10.1139/t01-031

[30] Hathaway, R.L. and Penny, D. (1975) Root Strength in Some Populus and Salix Clones. New Zealand Journal of Botany, 13, 333-344. https://doi.org/10.1080/0028825X.1975.10430330

[31] Westerlund, F.V., Campbell, R.N., Grogan, R.G. and Duniway, J.M. (1978) Soil Factors Affecting the Reproduction and Survival of Olvidium brassicae and Its Transmission of Big-Vein Agent to Lettuce. Phytopathology, 68, 927-935. https://doi.org/10.1094/Phyto-68-927

[32] Riestenberg, M.M. and Sovonick-Dunford, S. (1983) The Role of Woody Vegetation in Stabilizing Slopes in the Cincinnati Area. Ohio Geological Society America Bulletin, 94, 506-518. https://doi.org/10.1130/0016-7606(1983)94<506:TROWVI>2.0.CO;2

[33] Abe, K. and Iwamoto, M. (1986) Preliminary Experiment on Shear in Soil Layers with a Large Direct Shear Apparatus. Japanese Forestry Society, 68, 61-65.

[34] Riestenberg, M.M. (1994) Anchoring of Thin Colluvium by Roots of Sugar Maple and White Ash on Hillslopes in Cincinnati. US Government Printing Office, 2059.

[35] Abe, K. and Iwamoto, M. (1986) An Evaluation of Tree-Root Effect on Slope Stability by Tree-Root Strength. Japanese Forestry Society, 68, 505-510.

[36] Bischetti, G.B., Chiaradia, E.A., Simonato, T., Speziali, B., Vitali, B., Vullo, P. and Zocco, A. (2005) Root Strength and Root Area Ratio of Forest Species in Lombardy (Northern Italy). Plant Soil, 278, 11-22. https://doi.org/10.1007/s11104-005-0605-4

[37] Hales, T.C., Cole-Hawthorne, C., Lovell, L. and Evans, S.L. (2013) Assessing the Accuracy of Simple Field Based Root Strength Measurements. Plant Soil, 372, 553-565. https://doi.org/10.1007/s11104-013-1765-2

[38] Hales, T.C. and Miniat, C.F. (2016) Soil Moisture Causes Dynamic Adjustments to Root Reinforcement that Reduce Slope Stability. Earth Surface Processes and Landforms, 42, 803-813. https://doi.org/10.1002/esp.4039

[39] Craft, C.B., Reader, J., Sacco, J.N. and Broome S.W. (1999) Twenty-Five Years of Ecosystem Development of Constructed Spartina alterniflora (Loisel) Marshes. Ecological Applications, 9, 1405-1419. https://doi.org/10.1890/1051-0761(1999)009[1405:TFYOED]2.0.CO;2 
[40] Broome, S.W., Seneca, E.D. and Woodhouse, Jr., W.W. (1986) Long-Term Growth and Development of Transplants of the Salt-Marsh Grass Spartina alterniflora. Estuaries, 9, 63-74. https://doi.org/10.2307/1352194 